DOI: https://doi.org/10.47405/mjssh.v5i6.423

\begin{tabular}{|c|c|}
\hline - & Malaysian Journal of Social Sciences and Humanities (MJSSH) \\
\hline $\begin{array}{l}\text { Malaysian Journal of } \\
\text { Socail chelences and }\end{array}$ & Volume 5, Issue 6, June 2020 \\
\hline (MJ SSH & e-ISSN : 2504-8562 \\
\hline & $\begin{array}{l}\text { Journal home page: } \\
\text { www.msocialsciences.com }\end{array}$ \\
\hline
\end{tabular}

\title{
Quality of Life Among Malaysian University Students: A Cross-Sectional Study
}

\author{
Norshella Syakila Binti Kadir'1, Patricia Pawa Pitil'1, Wan Juliana Emeih Wahed ${ }^{2}$ \\ 1 Faculty of Sports Science and Recreation, Universiti Teknologi MARA (UiTM), Cawangan Sarawak, Kampus \\ Samarahan, Sarawak \\ 2Faculty of Art and Design, Universiti Teknologi MARA (UiTM), Cawangan Sarawak, Kampus Samarahan, Sarawak
}

Correspondence: Patricia Pawa Pitil (patriciapawa@uitm.edu.my)

\begin{abstract}
Quality of life reflects the health of individuals, physically and mentally. The aim of this study is to evaluate the quality of life among university students. A total sample of $N=377$ full-time students from various faculties of a single university were recruited following a cross-sectional study design. The World Health Organization QOL-BREF questionnaire was administered to measure the quality of life in four domains: physical quality, psychological quality, social relationship quality and environment quality. The total quality of life score obtained was $64.33 \pm 8.02$, which is in the fair category. For demographic comparisons, all domains were similar in distribution, except for age groups in the psychological health domain and sports involvement in the physical health domain. Older students reported a significantly higher mean scores for psychological health compared to the younger age group, while student-athletes scored higher in physical health than the non-athletes. Environment was scored lowest at $(13.25 \pm 1.78)$, while social relation was rated highest at $(15.10 \pm 3.07)$ among the participants. The overall quality of life and general health, and physical domains exhibited significant positive relationships, but some nonsignificant relationships were observed among student-athletes. Understanding the quality of life among university students would provide a beneficial information on their well-being. This study should become a benchmark to conduct other studies on similar topic especially among young adults. University counsellors and student's affair departments should acknowledge this study as a reference for organizing students development programs and planning for intervention in improving students' productivity if needed.
\end{abstract}

Keywords: quality of life, health, well-being, university students

\section{Introduction}

The World Health Organization (WHO) characterizes the quality of life (QoL) as a person's impression of their situation in life with regards to the way of life and value systems wherein they live, and in connection to their objectives, desires, standards and concerns (WHO, 1996). It is an expansive going idea influenced in a complicated way by the individual's physical wellbeing, mental state, individual beliefs, social connections, and their relationships to salient features of their condition. Therefore, it is relevant to infer that QoL can be impacted by many factors.

University students are a unique population, because their concerns, burdens and worries differ from other population group (Powers et al., 1992). They are exposed to many kinds of stressors, such as academic demands, social issues, and financial problems (Chermonas \& Shapiro, 2013; Goff, 2011; 
Jimenez et al., 2010). These young adults are at a higher risk of disturbance in their physical and mental health, as the long-term lifestyle begins in their university years. A poor QoL among university students could lead to various psychosocial difficulties, such as poor interpersonal relationship, low self-esteem, and depression.

It is mentioned that tertiary education is highly stressful to the students (Habeeb, 2010; Sherina et al., 2003). When stress is perceived negatively or becomes excessive, it could affect both the health and academic performance (Kumar et al., 2014). Moreover, if the stress is prolonged and untreated, it would elicit helplessness and depression (Puthran et al., 2016), thereby placing the academic future of some students in jeopardy. Sustaining a healthy mind is of utmost importance to the students since they are prone to experience undue extreme amount of stress (Marshall et al., 2008), which can lead to adverse consequences on academic performance, achievement, and enhanced productivity (Arslan et al., 2009; Ducinskiene et al., 2003)

As the challenges of being university students are almost identical, assessment and understanding of the relationships of their demographics to their QoL will help administrators to plan for intervention or improvement programs development, which in turn would contribute towards a holistic well-being of the individual. Studies of QoL among university students in Malaysia are scarce, as most studies were conducted in other countries. Hence, there is a need to assess the QoL of university students from Sarawak, Malaysia to explore the association and influence of their demographics on four important domains of QoL which are physical health, psychological health, social relation, and environment health.

\section{Method}

\section{Participants and procedure}

A sample of university students from the Universiti Teknologi MARA Kampus Samarahan, Sarawak aged between 18 to 24 years old from various courses participated in this study. Using a stratified random sampling technique, participants were selected from each faculty and the selection included diploma and degree students. The participants were recruited by using an established sample size calculation (Krejcie \& Mogran, 1970). From a total population of 5000 students, the minimum sample size calculated was 357. In order to minimize the non-response rate, an additional number of participants were added, making the total participants as $N=377$. Ethical approval was also sought from the faculty's Research Ethics Committee.

This study used a cross-sectional design and was conducted from March 2019 to June 2019, using a self-administered questionnaire method. This type of study design collects data to make inference about a population of interest at one point in time (Lavrakas, 2008). Prior to data collection, approval was obtained from the university authority to conduct the study. Briefings were held among the participants to explain the objectives of the study and assistance was provided in completing the questionnaire. Any confusing terms or sentences were explained and noted. The participants took approximately 15 to 20 minutes to complete the questionnaire. No compensation was offered.

\section{Measures}

Demographic data were gathered; age, gender, faculty, and sporting background (athlete or nonathlete). The World Health Organization QoL-BREF (WHOQOL-BREF) (WHO, 1998b) was administered to assess QoL. This 26-item questionnaire is designed to assess individual perceptions on their positions in life in the context of four domains; Physical health (Q3, Q4, Q10, Q15, Q16, Q17, Q18), Psychological health (Q5, Q6, Q7, Q11, Q19, Q25, Q26), Social relationships (Q20, Q21, Q22), and Environment (Q8, Q9, Q12, Q13, Q14, Q22, Q23, Q24) (WHO, 1998a).

Item $1(\mathrm{Q} 1)$ and item $2(\mathrm{Q} 2)$ of the scale measure the overall perceived QOL and health perception of the participants, respectively. For questions 1 and 15, the scale ranges from 1 (Very poor) to 5 (Very 
DOI: https://doi.org/10.47405/mjssh.v5i6.423

good). For question 2 and 16 to 24, the scale ranges from 1 (Very dissatisfied) to 5 (Very satisfied). For question 3 to 6, the scale ranges from 1 (Not at all) to 5 (An extreme amount). For question 7 to 9, the scale ranges from 1 (Not at all) to 5 (Extremely). For question 10 to 14, the scale ranges from 1 (Not at all) to 5 (Completely). For question 25, the scale ranges from 1 (Never) to 5 (Always). Higher scores indicate higher QoL. The items were distributed in the Malay version of WHOQOL-BREF (Hasanah et al., 2003), so that it can be easily understood.

Content validity procedure was followed to assess the validity of the questionnaire. Experts from the field of health and behavioural science were referred to examine the internal validity. All items were accepted except for item 21 which was suggested to be eliminated from the questionnaire due to its irrelevance to our culture. The item addresses the matters related to sexual behaviour, which read, "Are you satisfied with your sex life?". A study by (Chen et al., 2006), rationalized the item removal due to the younger age of respondents. Thus, only 25 items were used to measure QoL of the participants in this study.

The internal consistency of WHOQOL-BREF was measured using Cronbach's alpha scores. Overall items observed a high reliability, $\alpha=0.903$. The reliability value above 0.8 is considered good. The closer the alpha value to 1 , the better is the reliability (Serakan \& Bougie, 2003).

\section{Data analysis}

Data analysis was performed using the Statistical Package for Social Science (SPSS) (SPSS for Windows, Version 25.0. Chicago, US). The four domains scores were calculated by summing up the scores of the corresponding items in each domain. The calculation was performed by following the WHOQOL-BREF manual (WHO, 1998a). All scores were transformed to reflect the total score of 4 20 for each domain. The total QoL mean score was calculated by summing up all the domains' mean scores and the mean scores of two items: overall QoL (Q1) and general health (Q2). Descriptive statistics were calculated in means and standard deviations, frequencies, and percentages. Normality was tested by using skewness (ranges between -1 to +1 ) and kurtosis (ranges between -1 to +1 ) (Kim, 2013), and found a normal distribution of scores. Significant differences in the four domains were assessed by using the Independent sample t-test for continuous variables according to the various demographic characteristics. Pearson correlation was performed to assess relationships between domains. A $p$-value $\leq 0.05$ was considered statistically significant.

\section{Results}

A majority of the participants were females $(76.4 \%)$ with the age group ranging from 18 to 20 years old $(70.8 \%)$ as presented in Table 1 . They were from three different races, Malay (43.2\%), Bumiputera Sarawak (38.2\%), and Bumiputera Sabah (18.6\%). More than half of the participants were at the diploma level of study (61.8\%) and the remaining were first degree students (38.2\%). In sports involvement, non-athletes made up the majority $(90.5 \%)$.

Table 1. Demographic profile of the participants $(N=377)$

\begin{tabular}{cc}
\hline Demographic & $\boldsymbol{n}(\mathbf{\%})$ \\
\hline Gender & $89(23.6)$ \\
Male & $288(76.4)$ \\
Female & \\
Age (years) & $267(70.8)$ \\
$18-20$ & $110(29.2)$ \\
$21-24$ & $163(43.2)$ \\
Race $\quad$ Malay & $144(38.2)$ \\
Bumiputera Sarawak & $70(18.6)$
\end{tabular}


Malaysian Journal of Social Sciences and Humanities (MJSSH), Volume 5, Issue 6, (page 11 - 18), 2020 DOI: https://doi.org/10.47405/mjssh.v5i6.423

Study level

Diploma

First degree

Sports involvement

Athlete

$36(9.5)$

Non athlete

$341(90.5)$

Table 2 shows the overall and general QoL. Majority of the participants rated their QoL as good, and very good $(72.7 \%)$, with only a few rated poor, and very poor $(1.8 \%)$. In rating for general health, a majority of the participants were satisfied, and very satisfied (61.2\%). Few rated very dissatisfied $(0.8 \%)$.

Comparisons by demographics of the mean scores of QoL domains are shown in Table 3. All domains showed similar distributions of mean scores in all demographics $(p>.05)$, except for sports involvement in physical health $(p=.025)$, and age groups in psychological health $(p=.014)$. There was a significant difference in physical health between athletes and non-athletes. Athletes $(14.87 \pm 1.68)$ reported a higher score for physical health than the non-athletes $(14.04 \pm 2.15)$. There was also a significant difference for psychological health between the age groups of $18-20$ years $(14.22 \pm 2.05)$ and $21-24$ years $(14.78 \pm 1.82)(p<.05)$.

Table 2. Overall and general QOL by rating scale $(N=377)$

\begin{tabular}{lc}
\hline & $\boldsymbol{n} \mathbf{( \% )}$ \\
\hline Overall QOL & $2(0.5)$ \\
Very poor & $5(1.3)$ \\
Poor & $96(25.5)$ \\
Neither poor nor good & $219(58.1)$ \\
Good & $55(14.6)$ \\
Very good & \\
General health & $3(0.8)$ \\
Very dissatisfied & $27(7.2)$ \\
Dissatisfied & $116(30.8)$ \\
Neither satisfied nor dissatisfied & $192(50.9)$ \\
Satisfied & $39(10.3)$ \\
Very satisfied & \\
\hline
\end{tabular}

Table 3 Mean scores of QOL domains by age groups, gender, study level and sports involvement of the participants

\begin{tabular}{lccccc}
\hline & $\begin{array}{c}\text { Total score } \\
\text { QOL }\end{array}$ & PQ & PsychQ & SRQ & EnvQ \\
\hline Overall & $64.33 \pm 8.02$ & $14.12 \pm 2.12$ & $14.39 \pm 2.00$ & $15.10 \pm 3.07$ & $13.25 \pm 1.78$ \\
$\quad$ Minimum & 86.50 & 20 & 19.33 & 20 & 19 \\
$\quad$ Maximum & 40.79 & 6.29 & 8 & 4 & 8 \\
\hline Gender & & & & & \\
Male & $64.69 \pm 8.55$ & $14.24 \pm 2.28$ & $14.28 \pm 2.15$ & $15.21 \pm 3.37$ & $13.39 \pm 1.95$ \\
Female & $64.23 \pm 7.86$ & $14.08 \pm 2.07$ & $14.42 \pm 1.96$ & $15.07 \pm 2.97$ & $13.20 \pm 1.72$ \\
$p$-value & .637 & .541 & .554 & .699 & .374 \\
Age (years) & & & & & \\
$18-20$ & $63.91 \pm 8.03$ & $14.10 \pm 2.12$ & $14.22 \pm 2.05$ & $15.07 \pm 3.09$ & $13.14 \pm 1.75$ \\
$21-24$ & $65.36 \pm 7.93$ & $14.17 \pm 2.14$ & $14.78 \pm 1.82$ & $15.18 \pm 3.02$ & $13.50 \pm 1.84$ \\
$p$-value & .111 & .789 & $.014 *$ & .750 & .071 \\
Study level & & & & & \\
Diploma & $64.00 \pm 7.80$ & $14.12 \pm 2.04$ & $14.27 \pm 2.01$ & $15.14 \pm 3.04$ & $13.14 \pm 1.74$ \\
Degree & $64.87 \pm 8.37$ & $14.11 \pm 2.25$ & $14.58 \pm 1.98$ & $15.04 \pm 3.12$ & $13.41 \pm 1.84$
\end{tabular}


Malaysian Journal of Social Sciences and Humanities (MJSSH), Volume 5, Issue 6, (page 11 - 18), 2020 DOI: https://doi.org/10.47405/mjssh.v5i6.423

\begin{tabular}{lccccc}
$p$-value & .309 & .969 & .145 & .759 & .153 \\
$\begin{array}{l}\text { Sports } \\
\text { involvement }\end{array}$ & & & & & \\
Athlete & $66.36 \pm 6.37$ & $14.87 \pm 1.68$ & $14.83 \pm 1.77$ & $15.72 \pm 2.91$ & $13.46 \pm 1.66$ \\
Non athlete & $64.12 \pm 8.15$ & $14.04 \pm 2.15$ & $14.34 \pm 2.02$ & $15.04 \pm 3.08$ & $13.22 \pm 1.79$ \\
$p$-value & .111 & $.025^{*}$ & .161 & .203 & .453 \\
\hline
\end{tabular}

*significant difference at $.05(p<.05)$. All variances were equalled $(p>.05)$ for comparison of scores.

PQ: Physical health; PsychQ: Psychological health; SRQ: Social relationship; EnvQ: Environment

The correlations between the domains and ratings for overall QOL and general health for participants who were athletes is shown in Table 4. There were no significant relationships between overall QOL and physical health with social relationship $(p>.05)$. Psychological health $(r=.397)$ and environment $(r=.472)$ were significantly correlated with overall QOL $(p<.05)$. On the other hand, physical health $(r=.376)$ was the only domain significantly correlated with general health $(p<.05)$. Others were not significant. Between the domains, physical health and social relationship, and environment and social relationship did not significantly correlate $(p>.05)$. Others were significant with positive correlations $(p<.05)$.

Table 4. Correlations between the QOL domains and rated overall QOL and general health among student-athletes $(\mathrm{n}=36)$

\begin{tabular}{lcccccc}
\hline & OvQOL & GenH & PQ & PsychQ & SRQ & EnvQ \\
\hline OvQOL & 1 & & & & & \\
GenH & $.359^{*}$ & 1 & & & & \\
PQ & .115 & $.376^{*}$ & 1 & & & \\
PsychQ & $.397^{*}$ & .117 & $.384^{*}$ & 1 & & \\
SRQ & -.091 & .031 & .315 & $.423^{*}$ & 1 & \\
EnvQ & $.472^{*}$ & .259 & $.487^{*}$ & $.575^{*}$ & .263 & 1 \\
\hline
\end{tabular}

*correlation is significant at $.05(p<.05)$

OvQOL: Overall quality of life: GenH: General health; PQ: Physical health; PyschQ: Psychological health; SRQ: Social relationship; EnvQ: Environment

Table 5. Correlation between the QOL domains and rated overall QOL and general health in non-athletes $(\mathrm{n}=341)$

\begin{tabular}{lcccccc}
\hline & OvQOL & GenH & PQ & PsychQ & SRQ & EnvQ \\
\hline OvQOL & 1 & & & & & \\
GenH & $.461^{*}$ & 1 & & & & \\
PQ & $.420^{*}$ & $.463^{*}$ & 1 & & & \\
PsychQ & $.442^{*}$ & $.488^{*}$ & $.557^{*}$ & 1 & & \\
SRQ & $.342^{*}$ & $.346^{*}$ & $.510^{*}$ & $.554^{*}$ & 1 & \\
EnvQ & $.369^{*}$ & $.457^{*}$ & $.527^{*}$ & $.608^{*}$ & $.484^{*}$ & 1 \\
\hline
\end{tabular}

*correlation is significant at $.05(p<.05)$

OvQOL: Overall quality of life: GenH: General health; PQ: Physical health quality; PyschQ:

Psychological health; SRQ: Social relationship; EnvQ: Environment

In contrast, all domains showed significant positive correlations with overall QOL and general health $(p<.05)(r=.342-.488)$ among the non-athletes (Table 5). Between the domains, all correlations were also found to be significant, $r=.484-.608(p<.05)$.

\section{Discussion}

The study on QoL is at interest globally due to more concerns being put on becoming healthy, physically and mentally. Therefore, the present study aims to explore the QoL among university students in Malaysia by demographics and sports involvement. 
The study revealed that the total mean score of QoL was fair $(64.33 \pm 8.02)$, where it should range between 25 to 125 . Higher scores represent greater levels of QoL. In the ratings of their overall and general health, a majority of the participants perceived it as good to very good and satisfied to very satisfied. This is similar to the findings by (Klemenc-Ketis et al., 2011), where the final year students exhibited a better QoL. The university students in Turkey (Nur et al., 2017) also revealed an acceptably good QoL. Even though the total scores were found to be at a fair level, the students' ratings on their overall and general health are not worrisome. The highest mean score was in social relation, while the lowest was in environment. This is not a surprise as at the age of young adults, who are away from their families, making a good social relation is a means to live a functional life as students. University faculty, classmates, non-teaching staff and peers are believed to be the strongest influences on the students' overall success in university (Wayt, 2012). The environment of the students' lives, whether living on campus or off-campus, might not be as good as they expected in terms of the health services, transportations, or their living spaces as examples. Thus, these are perceived with the least quality among them.

In comparing between the age groups, the psychological quality of the participants was higher in the older age group. A longer term of being students could influence the higher QoL compared to the newer students. In addition, those between the age groups of 21 to 25 years were most likely degree students, who are expected to be more matured and can handle their life better (Macpherson, 2002), thus perceiving a better psychological quality. This result is in contrast with Nur et al., (2017) suggested that physical functioning quality had no significant difference between the age groups (less than 20 and 20 and above).

Significant difference was observed in physical health, for sports involvement. Students who were athletes reported a higher quality in physical health than the non-athletes. This is expected, as the athletes are actively attending training sessions and competitions for their sports, which would influence their physical health quality. Participation in sports is always associated with physical and mental health (Penedo \& Dahn, 2005), thus this explains the finding. The present findings are also paralleled with a study by Çiçek (2018), where physical health quality was higher among sports department students than the other department students. However, the said study was in contrast with the present one, where it was observed that psychological, social relationship, and environment were significantly greater in quality among sports department students than the other departments students. Similar distribution of domains scores across gender, age groups (except psychological health), study levels, and sports involvement (except physical health) suggested that the students' QoL are similar regardless of those variables.

Being physically active as participation in sports, was reported to positively correlate with QoL (Kim et al., 2010). Therefore, a correlation analysis was performed between students who were athletes (student-athletes) and non-athletes. A very interesting result was found, where all domains were positively correlated between them and the overall QoL and general health among the non-athletes. The greater the scores, the greater the QoL by domains and rated overall and general QoL. In contrast, among the student-athletes, overall QoL was correlated with general health, psychological health, and environment. This finding shows that for students who are athletes, their overall QoL is influenced by general health, psychological and environment. Higher scores in overall QoL means greater quality in general health, psychological and environment or vice versa. On the other hand, general health was correlated with physical health. The higher the general health, the greater the physical health quality of the student-athletes and vice versa. Among the QoL domains, all were positively correlated, except for physical health and environment health with social relationship. Involvement in sports among the student-athletes could influence how they perceived their QoL as overall and general. Physical health of the participants was not influenced or related to overall QoL, but to general health, psychological and environment domains. This is a novel finding, where it is always expected that those who are active and participated in sports would have a better QoL and are influenced by its domains, though it is not exhibited in this study. Sports participation brought positive effects on subjective well-being (Huang \& Humphreys, 2012; Ruseski et al., 2014; Wicker et al., 2015), however, the present study shows that the student-athletes develop greater physical health and are influenced by psychological and environment quality. 
Universities play a crucial role in ensuring the QoL of the students is housed regardless of their demographics. It is a great news that students who are athletes has greater physical health, and those who are seniors or older are psychologically healthier than the younger students. Similar distribution of all domains also exhibited that the students were in good hands, even though their total score was fair. In consideration of this fair category, universities should be more aware of the students' physical, psychological, social relationship and environment. Environment quality in the present study was the lowest amongst the QoL domains, thus it needs extra attention. Participation in sports or physical activity should be encouraged too.

This study explored the influences of demographic variables on the students' QoL. Due to similar distribution, it is suggested that future studies should explore in more detail the influence of sociodemographic elements on the students' QoL. Their environment, for instance out campus renting or residential, living with friends or family, scholarship awardees or loan for tuition fees are important aspects to be assessed in association with QoL.

The advantages of this study are a large sample of participants from a single university, the use of valid and reliable instrument to measure QoL, and the face-to-face survey method employed in collecting the data. Feedback and assistance in completing the survey were the strengths of this study in data collection. On the other hand, the limitation is the small number of athletes who participated as respondents. To counter this limitation so that the statistical analysis is unbiased, the variances met the equal assumption, thus comparisons between groups were viable.

\section{Conclusion}

In conclusion, the QoL of the university students were fair, but acceptable, good, and satisfactory, based on the ratings. All domains were similar regardless of their demographics, except for physical health among student-athletes and psychological health among older students. QoL domains were correlated among the students in general, although some non-significant correlations were found among student-athletes. Further exploration of the QoL of university students is warranted, to ensure their overall well-being. This study should become a benchmark to conduct other studies on QoL especially among young adults. University counsellors and student affair departments should acknowledge this study as a reference for organizing students' development programs and plan for intervention if needed.

\section{References}

Arslan, G., Ayranci, U., Unsal., A., \& Arslantas, D. (2009). Prevalence of depression, its correlates among students, and its effect on health-related quality of life in a Turkish university. Ups Journal of Medical Science, 114(3), 170 - 177.

Chen, K. H., Wu, C. H., \& Yao, G. (2006). Applicability of the WHOQOL-BREF on early adolescence. Social Indicators Research, 79(2), 215 - 234.

Chermonas, W. M., \& Shapiro, C. (2013). Stress depression and anxiety among undergraduate nusring students. International Journal of Nursing Education Scholarship, 10(1), 255 - 266.

Ducinskiene, D., Kalediene, R., \& Pettrauskiene, J. (2003). Quality of life among Lithaunian University students. Acta Med Litu, 10(2), 76 - 81.

Goff, A. M. (2011). Stressors, academic performance and learned resourcefulness in baccalaureate nursing students. International Journal of Nursing Education Scholarship, 8(1).

Habeeb, K. A. (2010). Prevalence of stressors among female medical students Taibah University. Journal of Taibah University Medical Sciences, 5(2), 110 - 119.

Hasanah, C., Naing, L., \& Rahman, A. (2003). World Health Organization quality of life assessment: Brief version in Bahasa Malaysia. Medical Journal of Malaysia, 58(1), 79 - 88.

Huang, H., \& Humphreys, B. R. (2012). Sports participation and happiness: evidence from US microdata. Journal of Econ Psychology, 33, 776 - 793 
Jimenez, C., Navia-Osorio, P. M., \& Diaz, C. V. (2010). Stress and health in novice and experienced nursing students. Journal of Advanced Nursing, 66(2), 442 - 455.

Kim, H. Y. (2013). Statistical notes for clinical researchers: assessing normal distribution. Restor Dent Endod, 38(1), 52 - 54.

Kim, I., Choi, H., \& Davis, A. H. (2010). Health-related quality of life by type of physical activity in Korea. Journal of Community Health Nursing, 27(2), 96 - 106.

Klemenc-Ketis, Z., Kersnik, J., Eder, K., \& Colaric, D. (2011). Factors associated with health-related quality of life among university students. Srp Arh Celok Lek, 139(3 - 4), 197 - 202.

Krejcie, R. V., \& Mogran, D. W. (1970). Determining sample size for research activities. Educational and psychological measurement, 30(3), $607-610$.

Kumar, M., Shrama, S., Gupta, S., Vaish, S., \& Misra, R. (2014). Medical education effect of stress on academic performance in medical students - a cross-sectional study. Indian Journal of Physiological Pharmacology, 58(1), 81 - 86.

Lavrakas, P. J. (2008). Cross-sectional survey design. Encyclopedia of survey research methods.

Macpherson, K. (2002). Problem-solving ability and cognitive maturity in undergraduate students. Assessment and Evaluation in Higher Education, 27(1), 5 - 22.

Marshall, L. L., Allison, A., Nykamp, D., \& Lanke, S. (2008). Perceived stress and quality of life among doctor of pharmacy students. American Journal of Pharmacy Education, 72(6), 137.

Nur, N., Kibik, A., Kilic, E., \& Sumer, H. (2017). Health-related quality of life and associated factors among undergraduate university students. Oman Medical Journal, 32(4), 329 - 334.

Penedo, F. J., \& Dahn, J. R. (2005). Exercise and well-being: a review of mental and physical activity. Curr Opin Psychiatry, 18(2), 189 - 193.

Powers, C. B., Wisoski, P. A., \& Whitbourne, S. K. (1992). Age differences and correlates of worrying in young and elderly adults. Gerontologist, 32, 82 - 88.

Puthran, R., Zhang, M. W., Tam, W. W., \& Ho, R. C. (2016). Prevalence of depression amongst medical students: a meta-analysis. Medical Education, 50(4), 456 - 468.

Ruseski, J. E., Humphreys, B. R., Hallmann, K., Wicker, P., \& Breuer, C. (2014). Sport participation and subjective well-being instrumental variable results form German survey data. Journal of Physical Acitivity and Health, 11, 396 - 403.

Serakan, U., \& Bougie, R. (2003). Research methods for business: A skill building approach. Wiley \& Sons.

Sherina, M. S., Lekhraj, R., \& Nadarajan, K. (2003). Prevalence of emotional disorder among medical students in a Malaysian university. 2003, 2, $213-217$

Wayt, L. K. (2012). The impact of students' academic and social relationships on college student persistence University of Nebraska-Lincoln.

WHO. (1996). WHOQOL-BREF: Introduction, administration, scoring and generic version of the assessment: Field trial version. World Health Organization.

WHO. (1998a). WHOQoL user manual:facet definitions and response scales. World Health Organization, 61 - 71.

WHO. (1998b). The World Health Organization quality of life assessment (WHOQoL): development and general psychometric properties. Social Science Medicine, 46, 1569 - 1585.

Wicker, P., Coates, D., \& Breuer, C. (2015). The effect of a four-week fitness program on satisfaction with health and life. International Journal of Public Health, 60(1), 41 - 47. 